\title{
An operational dynamical neuro-forecasting model for hydrological disasters
}

\author{
Glauston R. T. de Lima ${ }^{1}$ - Leonardo B. L. Santos ${ }^{1}$ Tiago J. de Carvalho ${ }^{1,3}$. \\ Adenilson R. Carvalho ${ }^{1}$ - Fábio D. Cortivo ${ }^{2}$ Graziela B. Scofield ${ }^{1}$. \\ Rogério G. Negri
}

Received: 23 May 2016/Accepted: 25 May 2016/Published online: 13 June 2016

(C) Springer International Publishing Switzerland 2016

\begin{abstract}
In the last decades, artificial neural network has been increasingly applied in hydrological modeling given its potential to process the complex nonlinear relationships of the associated physical-environmental variables and produce a suitable solution (for instance, a forecasting model) in a relatively short time. In this scope, this work reports the design methodology and the operational results obtained with an artificial neural network-based model developed to forecast, with $2 \mathrm{~h}$ in advance, the level of a river in the mountainous region of Rio de Janeiro state in Brazil. This is an area susceptible to natural disasters with recent records of floods and landslides that caused environmental and socio-economic damage of large proportions. The proposed neural network uses an innovative learning algorithm (the quasi-Newton optimization method is applied to the slopes of each hidden activation function) and, as input features, values of rainfall and river level data collected from 8 monitoring stations located on studied watershed between 2013 and 2014. The results of the neural model, with NASH index greater than 0.86 , are promising making possible its operational use on an issuing flood alerts system.
\end{abstract}

Glauston R. T. de Lima

glauston.lima@cemaden.gov.br

1 National Centre for Monitoring and Early Warning of Natural Disasters (Cemaden), Estrada Doutor Altino Bondesan 500, Distrito de Eugênio de Melo (Rodovia Presidente Dutra, km 137,8), São José Dos Campos, SP 12247-016, Brazil

2 Institute of Science and Technology, UNESP-Univ. Estadual Paulista, São José Dos Campos, SP, Brazil

3 Federal Institute of Education, Science and Technology of São Paulo, Campinas, SP, Brazil
Keywords Hydrological disasters · Flood warnings · River level forecasting · Data-driven hydrological modeling . Artificial neural network

\section{Introduction}

Floods and flash floods are a kind of natural disaster very common in mountainous regions. The hilly and steep topography in these regions associated with other factors as the presence of sinuous rivers and small watersheds with short response time favor the occurrence of such events. Furthermore, due to the rapid urbanization of the flood plains and the lack of a spatial planning and land use by municipalities, floods of greater magnitude occur in urban areas causing human and material losses.

In Brazil, Kobiyama et al. (2004) stated that the natural disasters that cause the greatest human losses are floods, flash floods and landslides and Tucci (2001) reported that urban floods and their consequences are closely related to population growth and the increase in impermeable surfaces caused by urbanization.

Non-structural measures were taken to mitigate the negative impacts of these natural disasters. In 2008, the Instituto Estadual do Ambiente (INEA) has implemented the Flood Alert System (FAS) for the mountainous region of Rio de Janeiro State, which notifies citizens and authorities the possibility of landslides and floods. FAS operates several rainfall and river level data automatically, via mobile phone, every $15 \mathrm{~min}$. These data are available on INEA site in real time so, any user can follow current level of the rivers in each monitored municipality. Before long, in 2011, Brazilian Federal Government created the National Centre for Monitoring and Early Warning of Natural Disasters (Cemaden). Cemaden's mission is 
monitoring weather events able to trigger natural disaster like landslides, floods and flash flood in some Brazilian municipalities. Based on the construction of risk scenarios, Cemaden warnings are forwarded to the National Center for Disaster Risk Management (Cenad), which communicates the at-risk municipalities. Specially, in cases involving hydrological warnings, the analyzed context incorporates susceptibility and vulnerability indicators for people and dwellings, in addition to rainfall and flow data of watershed upstream associated with risk area (Souza et al. 2015).

Forecast river overflows in advance is fundamental for issuing early warnings to allow agencies like civil defense acting in time to avoid worse damage to the population in the risk areas. However, some flood's precursors meteorological events, like heavy convective rainfall, can occur in very small spatial scale and can have very fast genesis and evolution. In such cases, it is more difficult to forecast the consequent flood with the necessary advance while maintaining the desirable accuracy. Therefore, in order to achieve a good advance-accuracy tradeoff on flood warnings, hydrological modeling research groups have worked in the calibration of physical models for several Brazilian river watersheds. However, towards the same purpose, another line of research in hydrological modeling is focused on developing so-called data-driven models.

In this context, this work presents an approach to forecast the level of rivers using an innovative artificial neural network (ANN). The approach uses instances of observed rainfall and river level values as ANN inputs and then the ANN is able to forecast, up to $2 \mathrm{~h}$ in advance, the river level in a specific point of interest. To verify the robustness and effectiveness of proposed method, we present results for a case study in the mountainous region of Rio de Janeiro State, which recently suffered a major natural disaster. Particularly for this study, the ANN was trained to perform level forecasts in the Grande River. Once the point of interest for level forecasts in Grande River was set, a GIS-based procedure (Carvalho et al. 2015) could be applied to define the watershed upstream of the point. The hydrological stations of the watershed selected through this GIS-based procedure provided the input data to the ANNbased hydrological forecast.

Besides this introduction, the article is organized into the following sections: literature review on ANN use in hydrological modeling is presented in the Sect. 2; Sect. 3 describes the study area, the database employed to design the ANN, a scheme of database on-line access for future operational use of the neural model in real time and also the ANN architecture and its training algorithm; Sect. 4 presents and discusses the obtained results and, finally, Sect. 5 addresses the concluding remarks.

\section{Related works}

ANN is an efficient tool to produce in a relatively short time satisfactory solutions in process modeling with nonlinear input-output relationship. That is why, the use of ANN in hydrological modeling, generally characterized by a complex dependence between climatic and topographical variables, has increased since the $90 \mathrm{~s}$ and, under certain conditions (Hsu et al. 1995; Abrahart and See 2007), it is an option as good as or even better than the traditional physical and conceptual models.

A number of studies addressing issues such as the choice, sample intervals and preprocessing of the variables in the training database, techniques to find the best architecture, improved learning algorithms, generalization ability beyond the limits of the training range, performance comparison among different ANN and among ANN and other hydrological modeling/forecast approaches, have reported excellent results obtained with ANN in rainfall-runoff modeling, river streamflow simulating and flood forecasting for different watersheds (e.g. Karunanithi et al. 1994; Dawson and Wilby 1998, 1999; Imrie et al. 2000; Varoonchotikul 2003; Cigizoglu 2005; Anctil and Rat 2005; Shamseldin 2010; Araujo et al. 2011; Adamowski et al. 2012; Elsafi 2014; Shoaib et al. 2014; Banihabib 2016).

The subject was also comprehensively reviewed first in Dawson and Wilby (2001) and more recently in Abrahart et al. (2012). These surveys indicated as challenges for the ANN hydrological modeling research community the adoption of unified and consistent procedures for the selection and preprocessing of input variables, common benchmark data sets, more rigorous evaluation metrics that allow the comparison among models and attaching the ANN forecasts with confidence interval to enable its operational use. Solutions for some of these issues (benchmark data sets and confidence interval), have already been addressed (e.g. Srivastav et al. 2007; Kasiviswanathan et al. 2013; Newman et al. 2015; Kasiviswanathan and Sudheer 2016).

This study also offers some contributions, following emphasized: there are few studies dealing with data-driven models toward river level forecast on Rio Grande, so it seems worthy to develop a ANN-based model for this purpose on this watershed (which does not prevent the model to be tested in other Brazilian watersheds with similar characteristics (e.g. Dornelles et al. 2013); although the proposed ANN use a standard architecture, the training is performed with an innovative learning algorithm in which the Newton's method is applied to optimize not only weights and bias but also others ANN parameters that are normally kept fixed by the most of learning algorithm (we must emphasize that our ANN has already been applied 


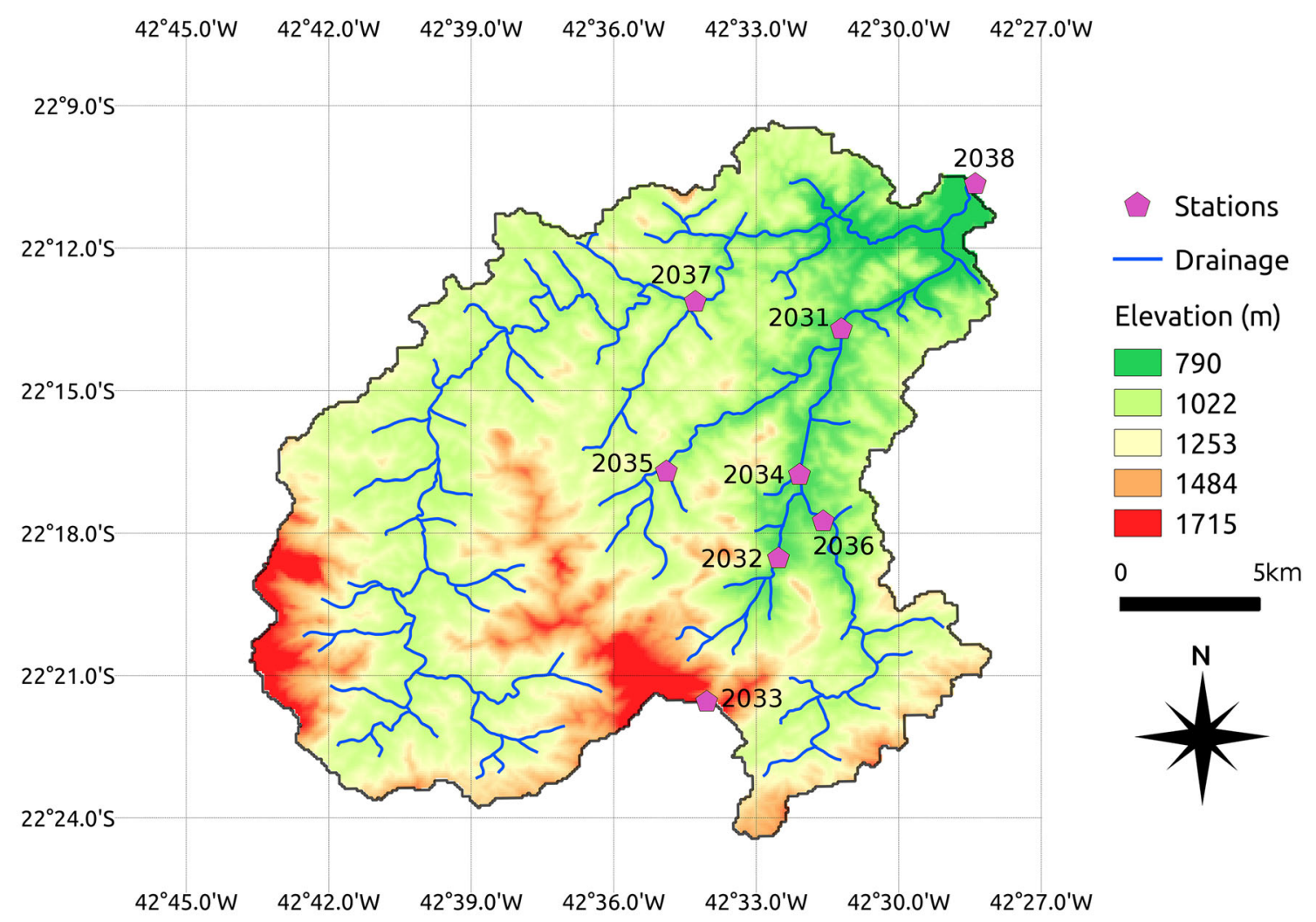

Fig. 1 Map of the studied area in Grande River watershed at mountainous region of the Rio de Janeiro State. (INEA monitoring stations along the watershed are identified by their numbers)

successful to solve others estimation/prediction tasks (Cortivo et al. 2012a, c), but its design was adapted to meet the specificities of the current hydrological modeling task); considering that the studied watershed have fast response to rainfall, develop a neural-model for short-term warnings is challenging and although we have not yet used data from other sources as radar data, the first results are encouraging and comparable to those obtained using radar data (e.g. Teschl and Randeu 2006); the rainfall-level database is updated every 15 min (which is not very common in other studies), which enables to use the proposed neural model in real-time as decision-making support tool in a flood warnings system. Nevertheless, in the subsequent stages of this research, the authors intend to improve the neural model by testing it with data from other river basins with similar characteristics and attaching uncertainty quantification and confidence intervals to the forecasts.

\section{Materials and methods}

\section{Study area}

The study area corresponds to the downstream area of Banquete station located at Grande River watershed, as shown in Fig. 1. The delimitation of the study area was done using TerraHidro software (Rosim et al. 2008) and the SRTM 30 m Digital Terrain Model. The watershed elevation goes from approximately 790-1715 m above sea level, corresponding to a significant altitude gradient. Nova Friburgo and Bom Jardim are two small cities located along the Bengalas River, which is the main tributary associated with Grande River. The Bengalas River is formed by the confluence of two small rivers (Santo Antônio and Cônego) within the urban area of Nova Friburgo and flows into the Grande River in the border with Bom Jardim. Based on empirical evidences collected by the local civil defense, the response time of this watershed is of approximately $2 \mathrm{~h}$. Furthermore, combining strong and disordered human occupation in Nova Friburgo with a tributary of Grande River that cross the region, occurrences of floods and flash floods frequently become natural disasters in the region, with serious damage to the local population.

According to the Köppen-Geiger system (Peel et al. 2007), the climate in the mountainous region of Rio de Janeiro state is classified as "Cwa" with fresh and dry winters and mild and wet summers. It is observed that the months from November to March correspond to the rainy season and the winter months (June, July and August) have 
Table 1 INEA monitoring stations in the studied area of the Grande River watershed

\begin{tabular}{lllllc}
\hline Station name (number) & Type & Latitude & Longitude & Municipality & Monitored river \\
\hline Banquete (2038) & Hydrological & $22^{\circ} 10^{\prime} 39^{\prime \prime} \mathrm{S}$ & $42^{\circ} 28^{\prime} 23^{\prime \prime} \mathrm{W}$ & Bom Jardim & Grande \\
Ponte Estrada Dona Mariana (2037) & Hydrological & $22^{\circ} 12^{\prime} 57^{\prime \prime} \mathrm{S}$ & $42^{\circ} 34^{\prime} 14^{\prime \prime} \mathrm{W}$ & Nova Friburgo & Grande \\
Conselheiro Paulino (2031) & Hydrological & $22^{\circ} 13^{\prime} 42^{\prime \prime} \mathrm{S}$ & $42^{\circ} 31^{\prime} 12^{\prime \prime} \mathrm{W}$ & Nova Friburgo & Bengala \\
Venda das Pedras (2035) & Hydrological & $22^{\circ} 16^{\prime} 42^{\prime \prime} \mathrm{S}$ & $42^{\circ} 34^{\prime} 53^{\prime \prime} \mathrm{W}$ & Nova Friburgo & Córrego D́antas \\
Suspiro (2034) & Hydrological & $22^{\circ} 16^{\prime} 46^{\prime \prime} \mathrm{S}$ & $42^{\circ} 32^{\prime} 05^{\prime \prime} \mathrm{W}$ & Nova Friburgo & Bengala \\
Ypu (2036) & Hydrological & $22^{\circ} 17^{\prime} 45^{\prime \prime} \mathrm{S}$ & $42^{\circ} 31^{\prime} 35^{\prime \prime} \mathrm{W}$ & Nova Friburgo & Santo Antônio \\
Olaria (2032) & Hydrological & $22^{\circ} 18^{\prime} 31^{\prime \prime} \mathrm{S}$ & $42^{\circ} 32^{\prime} 31^{\prime \prime} \mathrm{W}$ & Nova Friburgo & Cônego \\
Pico Caledônia (2033) & Pluviometric & $22^{\circ} 21^{\prime} 33^{\prime \prime} \mathrm{S}$ & $42^{\circ} 34^{\prime} 02^{\prime \prime} \mathrm{W}$ & Nova Friburgo & - \\
\hline
\end{tabular}

the lowest monthly rainfall totals compared to other seasons, showing that the dry and rainy seasons are well demarcated (Oliveira 2014).

Floods in Nova Friburgo occur mainly during the summer (November to March) and are caused by different phenomena such as summer storms and squall lines. Evening summer storms are quite frequent and its genesis and evolution are fast and located. Squall lines are, generally, associated with heavy rainfall and winds gusts, consisting primarily of a set of aligned cumulonimbus moving in a uniform manner during its lifetime that goes from a few hours up to a day (Silva Dias 1987).

\section{Database}

The database used in this study was collected from eight INEA monitoring stations as listed in the Table 1. For each station, the table shows name (number), type, geographical coordinates, the corresponding municipality and the monitored river (see Fig. 1 where each station is identified by its number).

Database is composed of rainfall data from one pluviometric station (study area headwaters), and rainfall and river level ${ }^{1}$ data from seven hydrological stations. Thus, each input instance corresponds to a feature vector of dimension 15 (eight rainfall values and seven level values). These data were collected between 2013 and 2014 with 15-min temporal resolution.

It is important to highlight that, this work models the problem using a data-driven approach for predicting the level of Grande River at Banquete station (study area outlet). Keeping it in mind, the output instances (the desired responses for the input instances) in the database are represented by the level of Grande River at this station.

Future goal of research is the implementation of the neuro-forecasting model that currently is under development, to an operational version in order to validate it, and

\footnotetext{
1 This work uses level data instead of flow data since rating curves are no available to the conversion.
}

finally integrate it to the Cemaden flood warnings support tools. This will require accessing the databases and making the predictions in real time. For databases available via Web Service (as the above INEA database used in this study), the on-line data reading process for real time forecasts is described below.

\section{Operational implementation}

Figure 2 shows the procedures for the operational implementation of proposed neuro-forecasting model based on data provided by monitoring stations. The procedures may be summarized by five main steps:

1. The process is prepared to start every $15 \mathrm{~min}$ through a schedule in a CRON table (branch 1.1 in Fig. 2). This schedule calls a Python script responsible by fetching rainfall and river level data collected by monitoring stations. In order to perform this fetch, Python script calls a web service (WS), provided by Cemaden, that allows querying data from a specific data collection platform (DCP), such as Cemaden or any other observational network (branch 1.2 in Fig. 2). Data delivered via WS are added to a database as soon as they are received ${ }^{2}$.

2. Once data are correctly received, Python script creates a data structure aligning rainfall and level river information of the eight stations considered in this work generating a text file (branch 1.3 in Fig. 2). This file feeds the inputs of the neuro-forecasting model (the MLP neural network).

3. Python script invokes a shell script (branch 1.4 in Fig. 2) that, via a system call trigger the ANN. The ANN will predict river level at target station (watershed outlet) for the future time scheduled in the entrance of the CRON (branches 1.4 and 1.5 in Fig. 2).

\footnotetext{
$\overline{2}$ In the case of Cemaden network, the DCP send data every 10 min and, when there is no rain at all, every hour.
} 


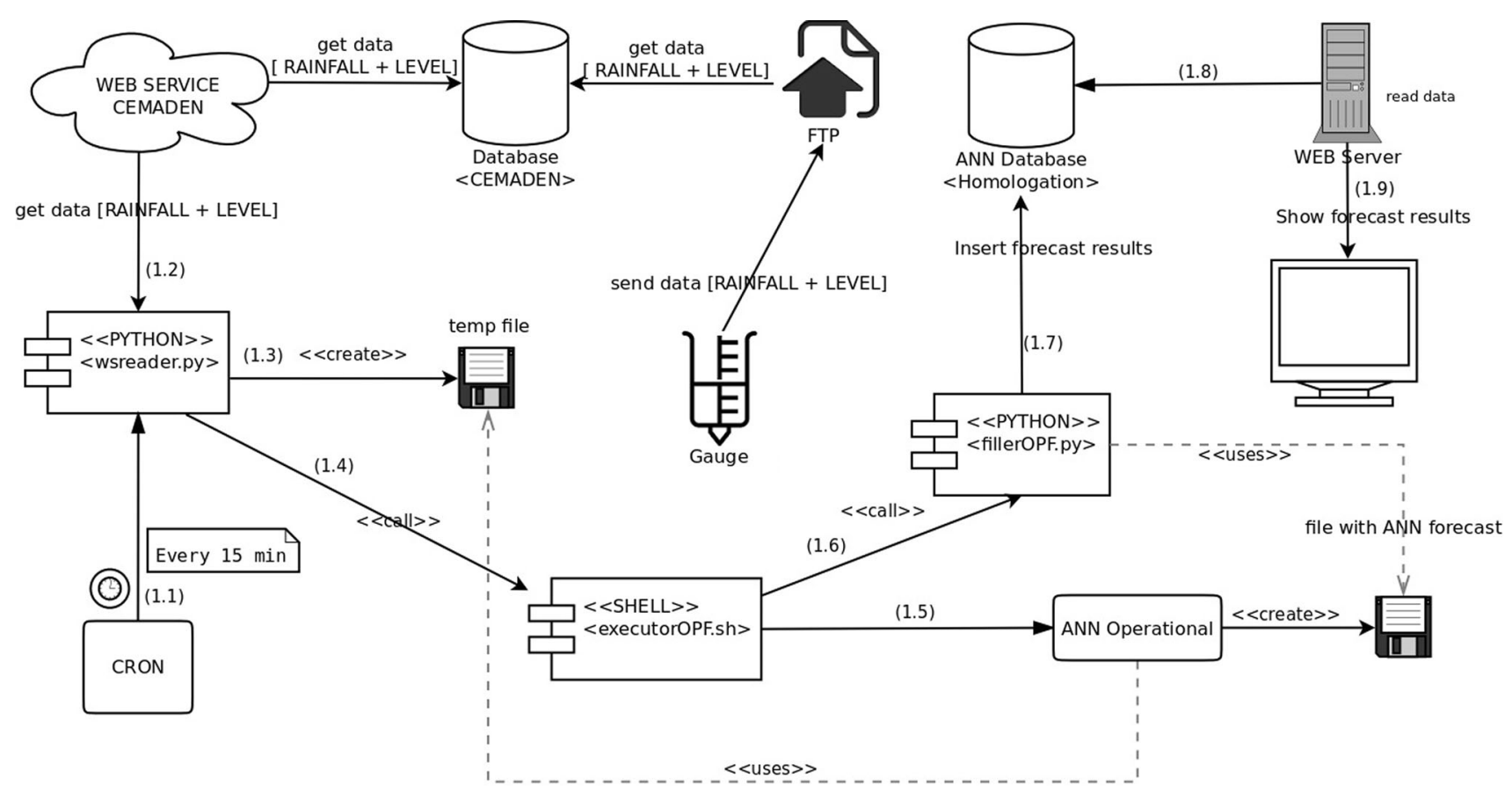

Fig. 2 Schematic of the neuro-forecasting process in real time for operational use including the steps from the on-line reading of a new instance (rainfall-level) to the output of the corresponding river level forecast

4. Once ANN forecasting is finished, another Python script starts to record the predicted values into forecast database (branches 1.6 and 1.7 in Fig. 2).

5. Finally, given recorded data on forecast database, we use a graphical interface coupled to a web server tool for displaying the results in a graphical format (branches 1.8 and 1.9 in Fig. 2). In our application, the Apache web server version 2.2.22 is used.

\section{The ANN}

ANN is a computational intelligence tool with proven potential to model many natural phenomena, for which there is no explicit mathematical formula linking inputs and outputs variables, only using observed values of inputoutput pairs of these variables as training data. In this regard, it is noteworthy the robustness of ANN (in terms of prediction or classification accuracy) against noisy and missing training data. In addition, ANN easily allows incorporating a priori knowledge of experts. Briefly, ANN is trained "to learn" the input-output relationships through an iterative process in which the weight assigned to each input attribute is adjusted to minimize the error between the ANN outputs and the true outputs (the output observed values). Once the learning process has been completed, it is expected that the ANN has good generalization ability and can properly respond to new data.
The standard multilayer perceptron MLP is the ANN used in this work to perform Grande River level forecasts based on rainfall and river level data. Thus, regarding network topology, input layer has 15 nodes (the same dimension as input instances) and is fully connected to a single hidden layer, which, in turn, is connected to the single output neuron. Hidden activations functions are sigmoid, while the output neuron employs a linear function. Learning algorithm used to train the network is outlined as follow.

Input instances of training set are arranged into a matrix $\mathbf{I}_{\mathbf{t}}$, where each column corresponds to an input instance (feature vector) composed by eight values of rainfall data and seven values of river level data. The corresponding observed outputs (values of river level data) are arranged into a vector $\mathbf{O}_{\mathbf{t}}$. The matrix of synaptic weights and the vector of biases are, respectively, $\mathbf{W}$ and $\mathbf{B}$. Based on these elements, the vector $\mathbf{O}_{\mathbf{n}}$ of the network responses to the training input instances can be represented as:

$\mathbf{O}_{\mathrm{n}}=\mathbf{O}_{\mathrm{n}}\left(\mathbf{I}_{\mathrm{t}}, \mathbf{W}, \mathbf{B}\right)$

However, besides weights and biases, other network parameters adjusted by the learning algorithm in training phase are the slopes of hidden activation functions. Hidden slopes updates were based on previous similar approaches (Fiori 2003; Cortivo et al. 2012a, b, c and Cortivo 2013). So, if $\mathbf{S}$ is the vector of slopes values, Eq. 1 can be rewritten as: 


$$
\mathbf{O}_{\mathrm{n}}=\mathbf{O}_{\mathrm{n}}\left(\mathbf{I}_{\mathrm{t}}, \mathbf{W}, \mathbf{B}, \mathbf{S}\right)
$$

Knowing the vectors $\mathbf{O}_{\mathbf{t}}$ and $\mathbf{O}_{\mathbf{n}}$, an error vector $\mathbf{E}$ is calculated by:

$$
\mathbf{E}=\mathbf{O}_{\mathrm{t}}-\mathbf{O}_{\mathrm{n}}
$$

and, the functional $\mathfrak{I}(\bullet)$ to be minimized over the network training is defined as:

$\mathfrak{J}\left(\mathbf{I}_{\mathbf{t}}, \mathbf{W}, \mathbf{B}, \mathbf{S}\right)=\sum_{i=1}^{N} E(i)^{2}$

where, $\mathrm{N}$ is the number of input training instances and $\mathrm{E}(\mathrm{i})$ is the network error for the i-th input training instance. It is important to figure out that the network training is done in a batch mode (Haykin 1998), so Eq. 4 is applied only at the end of each training step.

To improve stability and convergence of the learning, constraints were associated with the network parameters to be optimized (weights, biases and slopes). In the case of sigmoidal activation functions, slope constraint should be, by default, a positive value. Therefore, the corresponding updated values in the matrix $\mathbf{S}$ meet the constraint:

$0<\mathrm{s}_{\mathrm{j}} \leq \mathrm{s}_{\max }$

where $s_{j}$ is the slope of the sigmoid of the $j$-th hidden neuron and $s_{\max }$ is a predefined threshold to avoid the sigmoid degenerates to a step function.

In case of the output neuron, restriction associated with the linear slope is:

$$
-\mathrm{s}_{\min }<\mathrm{s}_{\mathrm{o}} \leq \mathrm{s}_{\max }, \mathrm{s}_{\mathrm{o}} \neq 0
$$

where $s_{\mathrm{o}}$ is the output slope, $s_{\min }$, and $s_{\max }$ are minimum and maximum values, respectively, predefined to avoid overflow.

Once the training of an ANN is a nonlinear optimization problem, there is no guarantee that global minimum will be achieved and an attractive idea is to reduce the search space, searching for a local minimum and expecting that goods results will be achieved. Search space reduction is obtained by applying constraints on weights and biases. Therefore, during the training process, values in matrix $\mathbf{W}$ and vector $\mathbf{B}$ are sought, so that to satisfy the following constraints:

$\mathrm{w}_{\min } \leq \mathrm{w}_{\mathrm{j}} \leq \mathrm{w}_{\max }$

$b_{\min } \leq b_{j} \leq b_{\max }$

The restrictions in the Eq. 7 are also important to avoid the saturation of neurons.

Quasi-Newton method was used to optimize the network parameters since it is more robust and precise than standard backpropagation algorithm, as shown in Cortivo et al. (2012b) and (c). Thus, observing constraints in the Eqs. 5,
6 and 7, the learning algorithm searches for a set of values $\{\mathbf{W}, \mathbf{B}, \mathbf{S}\}^{*}$ satisfying:

$\nabla \mathfrak{J}\left(\bullet,\{\mathbf{W}, \mathbf{B}, \mathbf{S}\}^{*}\right)=0$

In the $(\mathrm{k}+1)^{\mathrm{th}}$ iteration the set $\{\mathbf{W}, \mathbf{B}, \mathbf{S}\}_{(\mathrm{k}+1)}$ is given by:

$\{\mathbf{W}, \mathbf{B}, \mathbf{S}\}_{(\mathrm{k}+1)}=\{\mathbf{W}, \mathbf{B}, \mathbf{S}\}_{\mathrm{k}}+\Delta\{\mathbf{W}, \mathbf{B}, \mathbf{S}\}$

If $\{\mathbf{W}, \mathbf{B}, \mathbf{S}\}_{(\mathrm{k}+1)}$ is close to the "optimal" set $\{\mathbf{W}, \mathbf{B}, \mathbf{S}\}^{*}$, the term $\Delta\{\mathbf{W}, \mathbf{B}, \mathbf{S}\}$ can be calculated by the first order approximation of Eq. 8 derived from its expansion in Taylor series around $\{\mathbf{W}, \mathbf{B}, \mathbf{S}\}_{\mathrm{k}}$ and the Eq. 9 can be rewritten as:

$$
\begin{aligned}
\{\mathbf{W}, \mathbf{B}, \mathbf{S}\}_{(\mathrm{k}+1)}= & \{\mathbf{W}, \mathbf{B}, \mathbf{S}\}_{\mathrm{k}}+\mathbf{H}^{-1} \nabla \mathfrak{J} \\
& \left(\bullet,\{\mathbf{W}, \mathbf{B}, \mathbf{S}\}_{\mathrm{k}}\right)
\end{aligned}
$$

where, $\mathbf{H}^{-1}$ is the inverse of Hessian matrix in $\{\mathbf{W}, \mathbf{B}, \mathbf{S}\}_{\mathrm{k}}$.

Proposed strategies in ANN training step as use of quasi-Newton method and slopes update, result in a network with fast learning and very good generalization ability as demonstrated by the results presented and discussed in the Sect. 4.

\section{Metrics used to evaluate the neuro-forecasting model}

Four descriptive metrics were considered to assess the predictive accuracy of the neural model: the mean error (ME), the mean absolute error (MAE), the root mean square error (RMSE) and the Nash-Sutcliffe index (NASH). These metrics are given by the formulas in the Eq 11, 12, 13 and 14, respectively.

$\mathrm{ME}=\frac{\sum_{\mathrm{i}=1}^{\mathrm{N}}\left(\mathrm{Ot}_{\mathrm{i}}-\mathrm{On}_{\mathrm{i}}\right)}{\mathrm{N}}$
$\mathrm{MAE}=\frac{\sum_{\mathrm{i}=1}^{\mathrm{N}}\left|\mathrm{Ot}_{\mathrm{i}}-\mathrm{On}_{\mathrm{i}}\right|}{\mathrm{N}}$

RMSE $=\sqrt{\frac{\sum_{\mathrm{i}=1}^{\mathrm{N}}\left(\mathrm{Ot}_{\mathrm{i}}-\mathrm{On}_{\mathrm{i}}\right)^{2}}{\mathrm{~N}}}$

$\mathrm{NASH}=1-\frac{\sum_{\mathrm{i}=1}^{\mathrm{N}}\left(\mathrm{Ot}_{\mathrm{i}}-\mathrm{On}_{\mathrm{i}}\right)^{2}}{\sum_{\mathrm{i}=1}^{\mathrm{N}}\left(\mathrm{Ot}_{\mathrm{i}}-\overline{\mathrm{Ot}}^{2}\right)}$

where, $\mathrm{N}$ is the number of instances in the test set, $\mathrm{Ot}_{\mathrm{i}}$ and $\mathrm{On}_{\mathrm{i}}$ are, respectively, the $\mathrm{i}$-th observed and predicted output values and $\overline{\mathrm{Ot}}$ is the average of the $\mathrm{N}$ observed output values. 
ME is an important metric to assess whether the model tends to under or overestimates observed values, i.e. ME evaluates the systematic error of the model. On the other hand, MAE, RMSE and NASH are metrics very common and widely used to evaluate hydrological models. In special, the NASH metric is equivalent to $\mathrm{R}^{2}$, another important metric used to evaluate hydrological models (see, for instance, works cited in Sect. 2). Nash metric mainly indicates the accuracy of the model concern the highest observed values (Krause et al. 2005), what meets the intended use of the neuro-forecasting model proposed in this work.

\section{Results and discussions}

In order to design the neuro-forecasting model using the learning algorithm described in the Sect. 3.4, the database was split in training and test sets according to a chronological holdout scheme. Thus, the training set encompassed all instances between January 2013 and June 2014 while the test set corresponded to the remaining instances from July to November 2014. This resulted in training sets with approximately $77 \%$ of the total data. Besides, two ANN were designed considering two different prediction horizons: 15 and $120 \mathrm{~min}$. The parameters $\mathrm{w}_{\max }$ and $\mathrm{w}_{\min }$ as well $b_{\max }$ and $b_{\text {mim }}$ were set as 25 and -25 respectively, while $\mathrm{s}_{\max }$ and $\mathrm{s}_{\min }$ were set as 1.5 and $10^{-14}$, respectively. A maximum number of iterations was chosen as stopping criteria for the ANN training. The results yielded by the two neural models are shown in Figs. 3 and 4 (in Fig. 3, each timestamp in the abscissas axis corresponds to $15 \mathrm{~min})$.

Figure 3a compares the observed level values with 15 and 120 min neuro-forecasting results, for all instances in the test sets while Figs. 3b, c highlights two different moments when rainfall occurred in the watershed and the river's level rose from low values, between 0 and 0.1 meters, and quickly reached local peaks. Regarding the major peaks in Figs. 3b, c, the agreement between observed and forecast values is very good for both 15 and 120 min models. However, it may be noted that, preceding the major peaks, the neuro-forecasting results present short-term fluctuations (in the form of minor peaks) that not exist in the observed values. This mismatch (most evident in Fig. 3c) is greater for the 120 min model. The causes of this anomalous behavior will be investigated in order to refine the model. Even so, we still emphasize that in an early warning scenario more important than small and punctual mismatches is the accuracy of proposed neuroforecasting models into monitor the dynamic behavior of river level pointing out sudden increases.
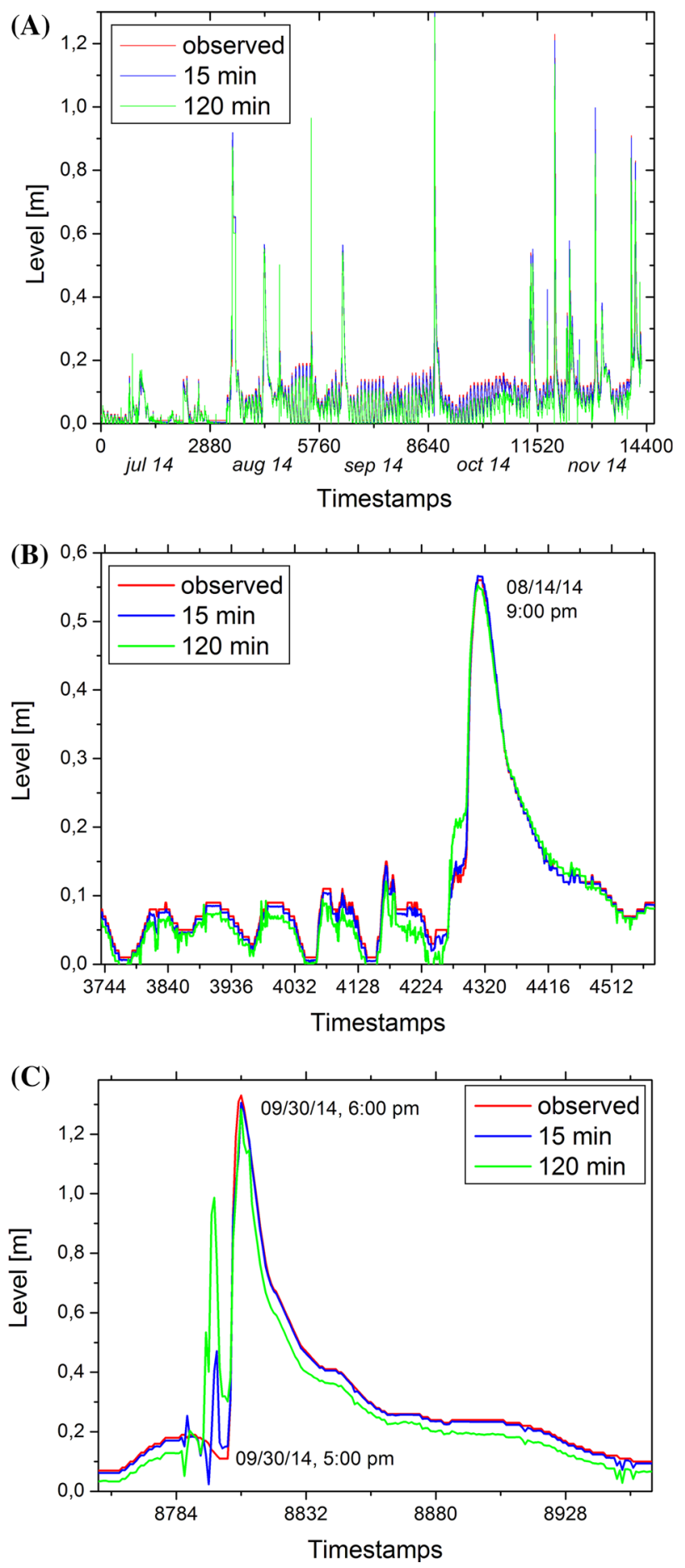

Fig. 3 Results for 15 and 120 min predictions; a observed and predicted values for all instances in the test sets; $\mathbf{b}, \mathbf{c}$ zoom in on some parts of the curves in (a) where occurred level peaks

Figure 4 shows the scatter diagram between the observed against 5 and $120 \mathrm{~min}$ neural-forecasted level values. The $120 \mathrm{~min}$ neuro-forecasting results usually presents slight underestimation of the river level compared 


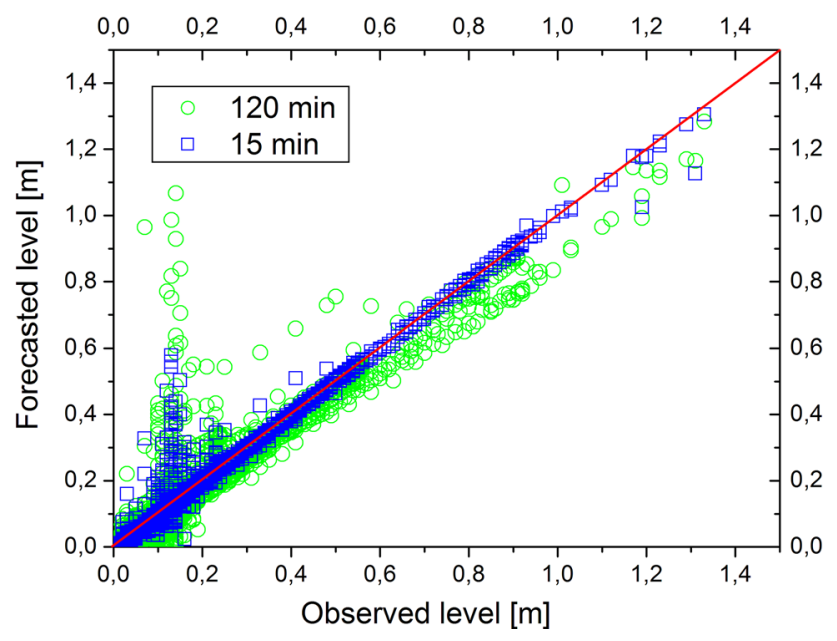

Fig. 4 Scatter plot between observed and neural-forecasted level values for prediction horizons of 15 and $120 \mathrm{~min}$

Table 2 Descriptive metrics of the neural forecasts for the two tested prediction horizons

\begin{tabular}{lll}
\hline Descriptive metric & \multicolumn{2}{l}{ Prediction horizon (min) } \\
\cline { 2 - 3 } & 15 & 120 \\
\hline ME (m) & 0.0048 & 0.0206 \\
MAE (m) & 0.0069 & 0.0265 \\
RMSE (m) & 0.0150 & 0.0401 \\
NASH & 0.9816 & 0.8688 \\
\hline
\end{tabular}

against observed river level, except for the observed river levels near of $0.12 \mathrm{~m}$. It happens when the input and output attributes are too small and the optimization process of our neuro-forecasting models became a little instable (probably this is related to the aforementioned fluctuations). However, thinking (again) in an early warning scenario, these flaws are not compromising, especially considering that for the vast majority of test instances did not occur relevant under or overestimation.

As quantitative results, neuro-forecasting results were assessed based on the descriptive metrics of the Sect. 3.5. These values are presented in Table 2.

From the MAE, RMSE, and NASH values, it is noted that if the prediction horizon increases the prediction error also increases. Based on the values of ME it is also possible to infer that the systematic error of the proposed neuroforecasting model tends to underestimate the predictions with an increase of this underestimation for larger prediction horizon.

As expected, 15 min neuro-forecasting model performed better than 120 min. However, a 120-min prediction horizon is particularly important for the studied watershed because this is approximately its response time and considering the Nash above 0.86, the same ANN-based approach would be applicable to others similar small watersheds with short time response favoring the occurrence of floods and flash floods mainly in the summertime. To this end, it would be necessary to train a similar ANN (same architecture and learning algorithm) but using the database of each watershed of interest.

Finally, regarding the viability of the operational use of model in real time in terms of execution times, we stress that:

- all experiments in this study were conducted on a Dell Optiplex 9020 machine with intel Core i7 4770, 8 GB RAM, running on a Linux operating system Ubuntu 14.04.01 on an environment virtualized by Oracle Virtual Box software;

- the average time required for the model training with the data set used in this study, measured after running 5 tests, was $307.4 \mathrm{~s}$;

- the execution time to generate a forecast for a new input instance using the trained model was $0.014 \mathrm{~s}$.

\section{Concluding remarks}

This work presented a new approach to perform river level prediction based on ANN. Using data from a minor interval (less than 2 years) the proposed method is able to achieve a NASH coefficient superior to 0.86 . Such method is already operational in an early warning system in Cemaden (Brazil) and its main objective is to support decisions makers in natural disasters scenarios.

Quantitative and qualitative experimental results of neuro-forecasting models trained to predict river level with 15 and $120 \mathrm{~min}$ in advance, show that proposed method is very robust to monitor the river level behavior. Even taking into account a few qualitatively inaccurate points of the results, we realize that such occurrences do not compromise the modeling approach and for an operational purpose, the model is very efficient and useful since it clearly depicts points where river rises and go down.

When compared against other literature methods, our proposed ANN-based model also present improvements as, for example, the ability to generalize even using a restricted number of training samples due to innovative learning algorithm applied in the training phase. Another point to note is the rapid availability of new data (each $15 \mathrm{~min}$ ) enabling the update of forecasts made with the model.

Finally, an important contribution of this method is the easiness to be extended and operationally applied in different watersheds with similar conditions (as, for example, the studied watershed in Dornelles et al. 2013), making possible anticipate episodes of natural disasters. 
As future works, we intend to test the method in other Brazilian watersheds and try to incorporate weather radar information in ANN training phase.

\section{References}

Abrahart RJ, See LM (2007) Neural network modelling of non-linear hydrological relationships. Hydrol Earth Syst Sci 11(1563):1579

Abrahart RJ, Anctil F, Coulibaly P, Dawson CW, Mount NJ, See LM, Shamseldin AY, Solomatine DP, Toth E, Wilby RL (2012) Two decades of anarchy? Emerging themes and outstanding challenges for neural network modelling of surface hydrology. Prog Phys Geogr 36:480-513

Adamowski J, Chan HF, Prasher SO, Sharda VN (2012) Comparison of multivariate adaptive regression splines with coupled wavelet transform artificial neural networks for runoff forecasting in Himalayan micro-watersheds with limited data. J Hydroinf 14:731-744

Anctil F, Rat A (2005) Evaluation of neural network streamflow forecasting on 47 watersheds. J Hydrol Eng 10:85-88

Araujo P, Astray G, Ferrerio-Lage JA, Mejuto JC, Rodriguez-Suarez JA, Soto B (2011) Multilayer perceptron neural network for flow prediction. J Environ Monit 13:35-41

Banihabib ME (2016) Performance of conceptual and black box models in flood warning systems. Cogent Eng 3:1127798

Carvalho T, Santos L B L, Luz E F P, Ishibashi R, Souza Jorge A A, Londe L R (2015) An operational open source approach for watersheds delimitation and characterization based on digital images and geographical databases. In: Proceedings of II International Conference on Information and Communication Technologies for Disaster Management (ICT-DM), Rennes

Cigizoglu HK (2005) Generalized regression neural network in monthly flow forecasting. Civ Eng Environ Syst 22:71-81

Cortivo FD (2013) Estimativa do perfil da concentração de clorofila em águas naturais com o uso de redes neurais artificiais. $\mathrm{Ph}$. D. Thesis (in Portuguese), Instituto Nacional de Pesquisas Espaciais

Cortivo FD, Chalhoub ES, Velho HFC (2012a) A committee of MLP with adaptive slope parameter trained by the quasi-Newton method to solve problems in hydrologic optics. In: Proceedings of the IEEE International Joint Conference on Neural Networks (IJCNN), Brisbane, Queensland

Cortivo FD, Chalhoub ES, Velho HFC (2012b) Estimativa do perfil da concentração de clorofila em águas naturais através de um perceptron de múltiplas camadas. Tendências em Matemática Aplicada e Computacional 13:233-246

Cortivo FD, Chalhoub ES, Velho HFC (2012b) Comparison of two learning strategies for a supervised neural network. In: Proceedings of the First International Symposium on Uncertainty Quantification and Stochastic Modelling, São Sebastião, São Paulo

Dawson CW, Wilby RL (1998) An artificial neural network approach to rainfall-runoff modelling. Hydrol Sci J Sci Hydrol 43(47):66

Dawson CW, Wilby RL (1999) A comparison of artificial neural networks used for river flow forecasting. Hydrol Earth Syst Sci 3(529):540

Dawson CW, Wilby RL (2001) Hydrological modelling using artificial neural networks. Progr Phys Geogr 25:80-108

Dias M A F da S (1987) Sistemas de mesoescala e previsão de tempo a curto prazo. Revista Brasileira de Meteorologia 2:133-150

Dornelles F, Goldenfum JA, Pedrollo OC (2013) Artificial neural network methods applied to forecasting river levels. Revista Brasileira de Recursos Hídricos 18:45-54
Elsafi SH (2014) Artificial neural networks (ANNs) for flood forecasting at Dongola station in the River Nile, Sudan. Alex Eng J 53:655-662

Fiori S (2003) Closed-form expressions of some stochastic adapting equations for nonlinear adaptive activation function neurons. Neural Comput 15:2909-2929

Haykin S (1998) Neural networks: a comprehensive foundation. Prentice Hall, Upper Saddle River

Hsu KL, Gupta HV, Sorooshia S (1995) Artificial neural network modeling of the rainfall-runoff process. Water Resour Res 31(2517):2530

Imrie C, Durucan S, Korre A (2000) River flow prediction using artificial neural networks: generalization beyond the calibration range. J Hydrol 233:138-153

Karunanithi N, Grenney W, Whitley D, Bovee K (1994) Neural networks for river flow prediction. J Comput Civ Eng 8:201-220

Kasiviswanathan KS, Sudheer KP (2016) Comparison of methods used for quantifying prediction interval in artificial neural network hydrologic models. Model Earth Syst Environ 2:22

Kasiviswanathan KS, Cibin R, Sudheer KP, Chaubey I (2013) Constructing prediction interval for artificial neural network rainfall runoff models based on ensemble simulations. J Hydrol 499:275-288

Kobiyama M, Checchia T, Silva RV, Schröder PH, Grando A, Reginatto GMP (2004) Papel da comunidade e da universidade no gerenciamento de desastres naturais. In Proceedings of Simpósio Brasileiro de Desastres Naturais, Florianópolis, Santa Catarina

Krause P, Boyle DP, Base F (2005) Comparison of different efficiency criteria for hydrological model assessment. Adv Geosci 5:89-97

Newman AJ, Clark MP, Sampson K, Wood A, Hay LE, Bock A, Viger R, Blodgett D, Brekke L, Arnold JR, Hopson T, Duan Q (2015) Development of a large-sample watershed-scale hydrometeorological dataset for the contiguous USA-dataset characteristics and assessment of regional variability in hydrologic model performance. Hydrol Earth Syst Sci 19:209-223

Oliveira NS (2014) Relação entre chuva e deslizamento em Nova Friburgo/RJ. M.S. Thesis (in Portuguese), Universidade Federal do Rio de Janeiro

Peel MC, Finlayson BL, McMahon TA (2007) Updated world map of the Köppen-Geiger climate classification. Hydrol Earth Syst Sci 11:1633-1644

Rosim AMV, Monteiro Renno C D, Oliveira JRF (2008) Uma Ferramenta Open Source que Unifica Representações de Fluxo Local Para Apoio à Gesto de Recursos Hídricos no Brasil. Informática Publica 10:29-49

Shamseldin AY (2010) Artificial neural network model for river flow forecasting in a developing country. J Hydroinf 12(22):35

Shoaib M, Shamseldin AY, Melville BW (2014) Comparative study of different wavelet based neural network models for rainfallrunoff modeling. J Hydrol 515:47-58

Souza A, Silva ACS, Anaya LM, Rodrigues J, Santos LBL (2015) Abordagem computacional livre para classificação de Strahler em hidrografias brasileiras relacionadas a desastres naturais. Modell Sci Educ Learn 8:23-34

Srivastav RK, Sudheer KP, Chaubey I (2007) A simplified approach to quantifying predictive and parametric uncertainty in artificial neural network hydrologic models. Water Res Res 43:W10407

Teschl R, Randeu WL (2006) A neural network model for short term river flow prediction. Nat Haz Earth Syst Sci 6:629-635

Tucci CEM, da Motta Marques D M L (2001) Aspectos institucionais do controle das inundações urbanas. Avaliação e Controle da Drenagem Urbana, v2 edn. ABRH, Porto Alegre, pp 405-419

Varoonchotikul P (2003) Flood forecasting using Artificial neural networks. CRC Press, Boca Raton 